Supporting information for

\title{
Formation of oxidized gases and secondary organic aerosol from a commercial oxidant-generating electronic air cleaner
}

Taekyu Joo ${ }^{\mathrm{a}}$, Jean C. Rivera-Rios ${ }^{\mathrm{b}}$, Daniel Alvarado-Velez ${ }^{\mathrm{b}}$, Sabrina Westgate ${ }^{\mathrm{b}}$, Nga Lee Ng ${ }^{\mathrm{a}, \mathrm{b}, \mathrm{c}}$

${ }^{a}$ School of Earth and Atmospheric Sciences, Georgia Institute of Technology, Atlanta, Georgia 30332,

United States

${ }^{b}$ School of Chemical and Biomolecular Engineering, Georgia Institute of Technology, Atlanta, Georgia 30332, United States

'School of Civil and Environmental Engineering, Georgia Institute of Technology, Atlanta, Georgia 30332,

United States 


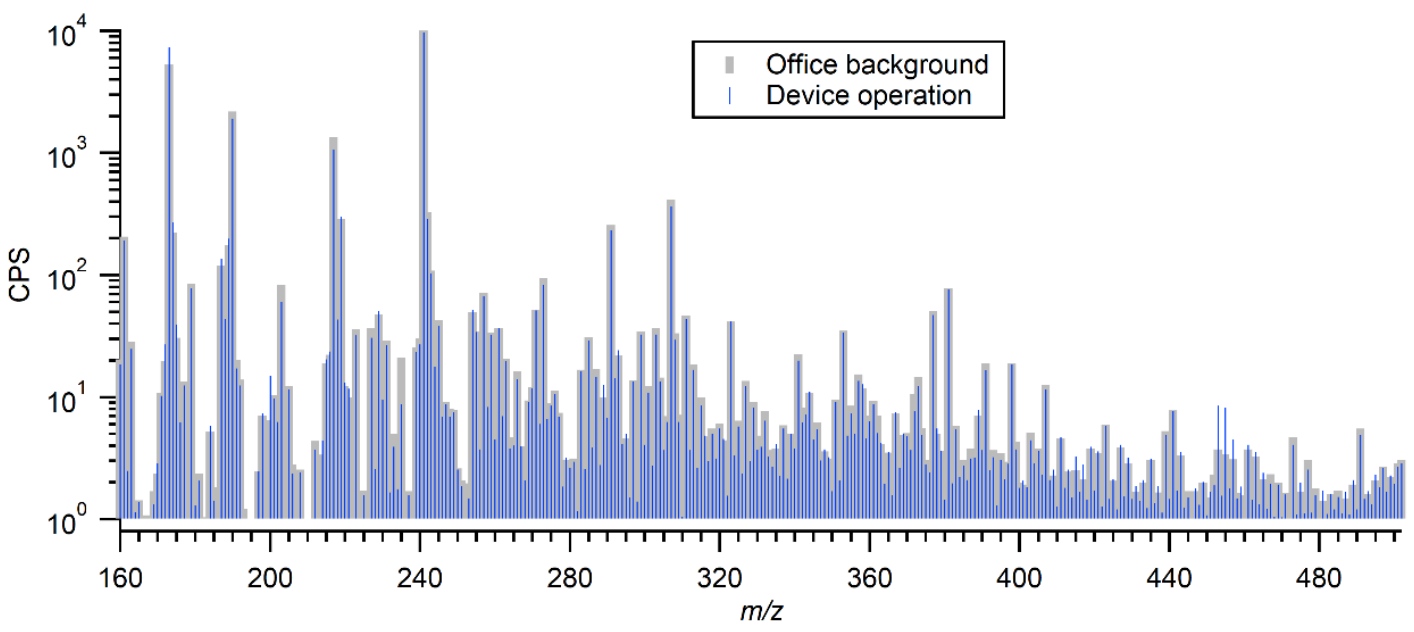

Figure S1. Mass spectra of HR-ToF-CIMS showing (a) grey: office background mass spectrum / blue: mass spectrum during hydroxyl generator operation 
(a)

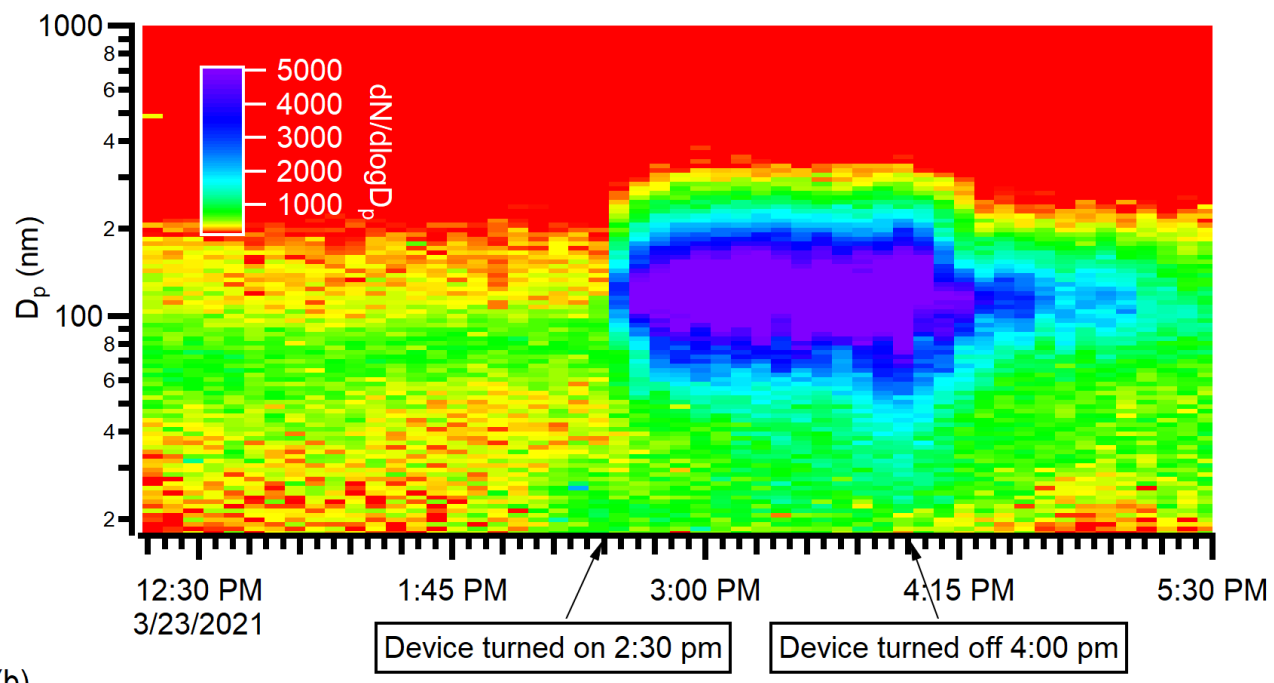

(b)

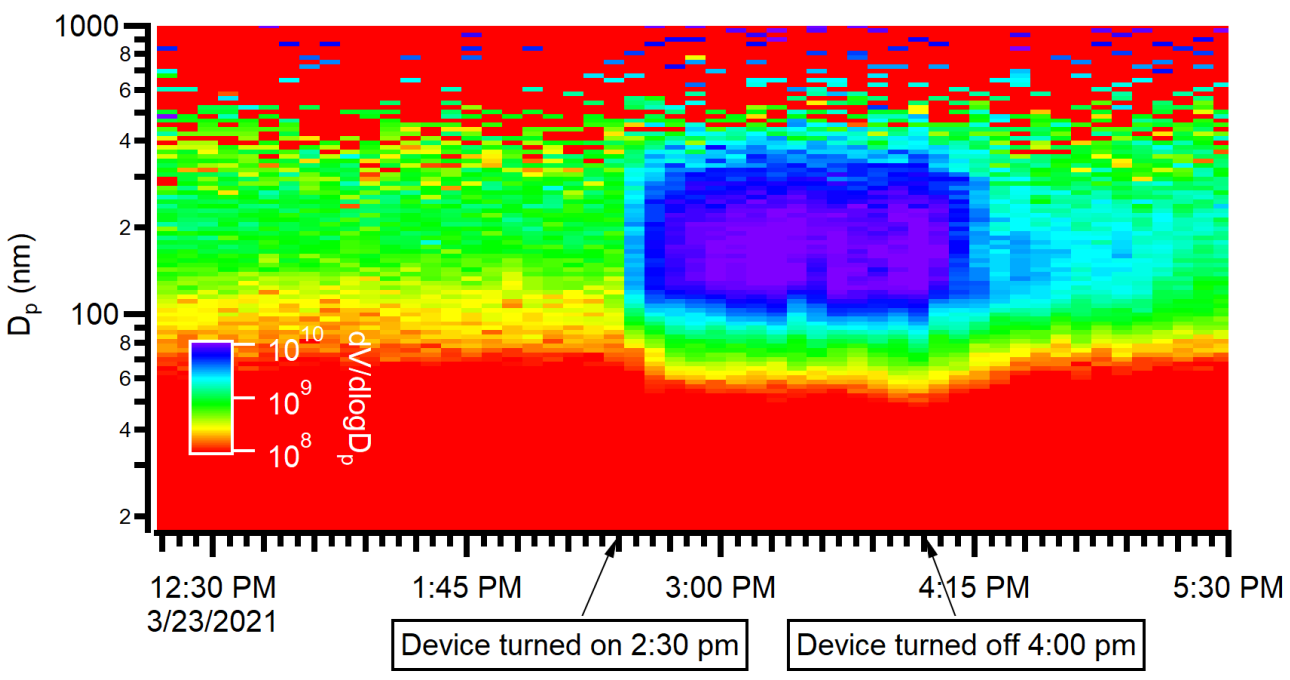

Figure S2. Size distribution of (a) particle number concentration $\left(\# \mathrm{~cm}^{-3}\right)$ and (b) particle volume concentration $\left(\mathrm{nm}^{3} \mathrm{~cm}^{-3}\right)$ from the office measurements. The color scale is in log scale. 
(a)

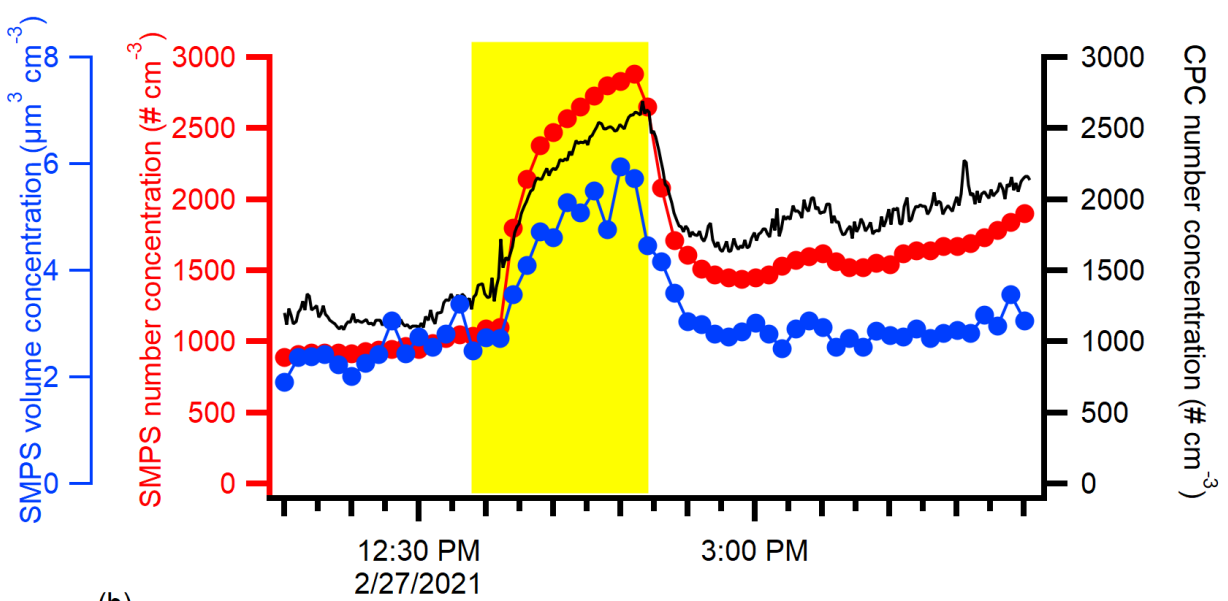

(b)

$2 / 27 / 2021$

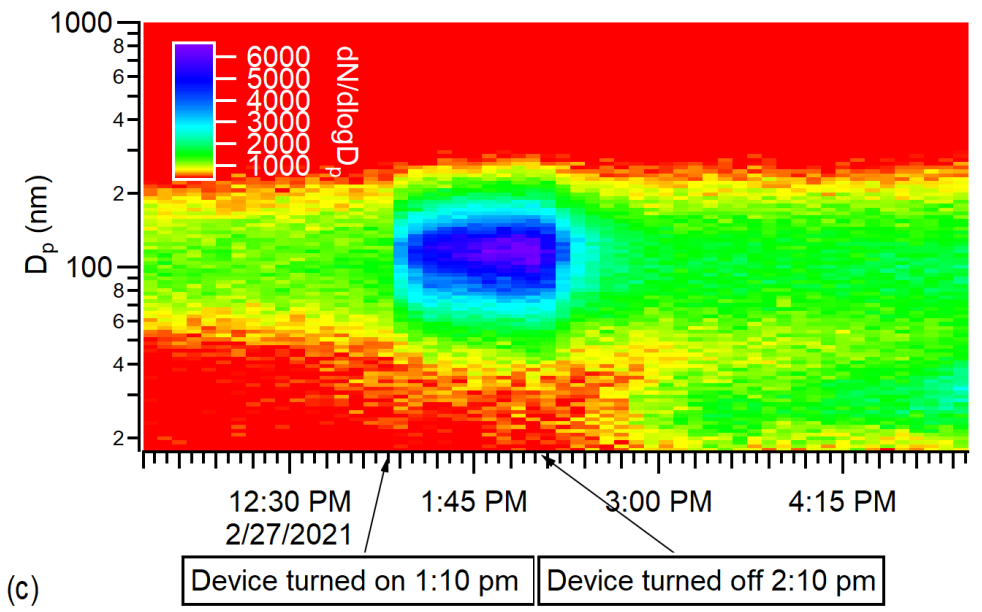

(c) Device turned on 1:10 pm Device turned off 2:10 pm

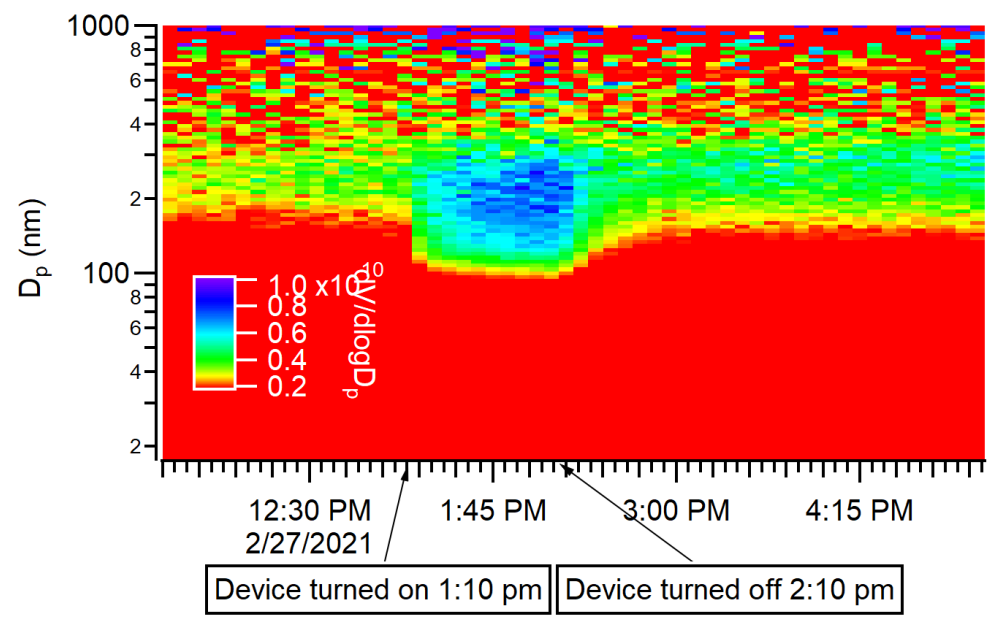

Figure S3. SMPS and CPC results from an experiment performed in a larger space (laboratory) than the office: (a) time series of number (CPC and SMPS) and volume concentrations (SMPS) with device operation period highlighted in yellow. Size distribution of (b) particle number concentration $\left(\# \mathrm{~cm}^{-3}\right)$ and (c) particle volume concentration $\left(\mathrm{nm}^{3} \mathrm{~cm}^{-3}\right)$. The color scale is in log scale. 


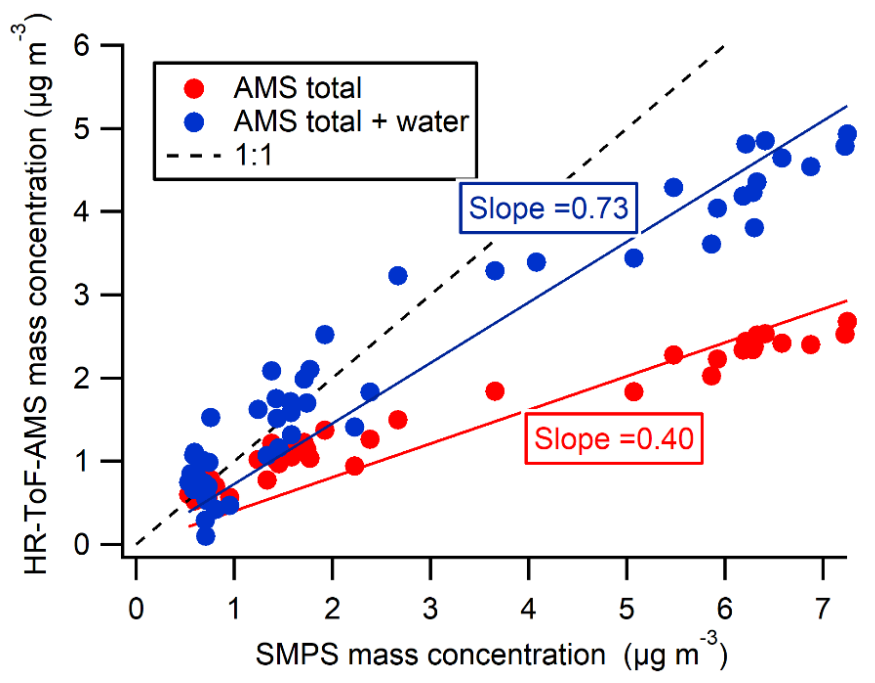

Figure S4. Comparison of AMS total mass concentration (sum of all non-refractory species) and SMPS mass concentration (intercepts set to zero) from the office measurements. The SMPS volume concentration was converted into mass concentration using density of the individual species: $1.75 \mathrm{~g} / \mathrm{cm}^{3}$ for sulfate, nitrate, and ammonium; $1.52 \mathrm{~g} / \mathrm{cm}^{3}$ for chloride; $1.79 \mathrm{~g} \mathrm{~cm}^{-3}$ for organics, estimated based on the elemental ratio of organics. ${ }^{1}$ Particle water from AMS was estimated based on the equation proposed in Engelhart et al. ${ }^{2}$ 

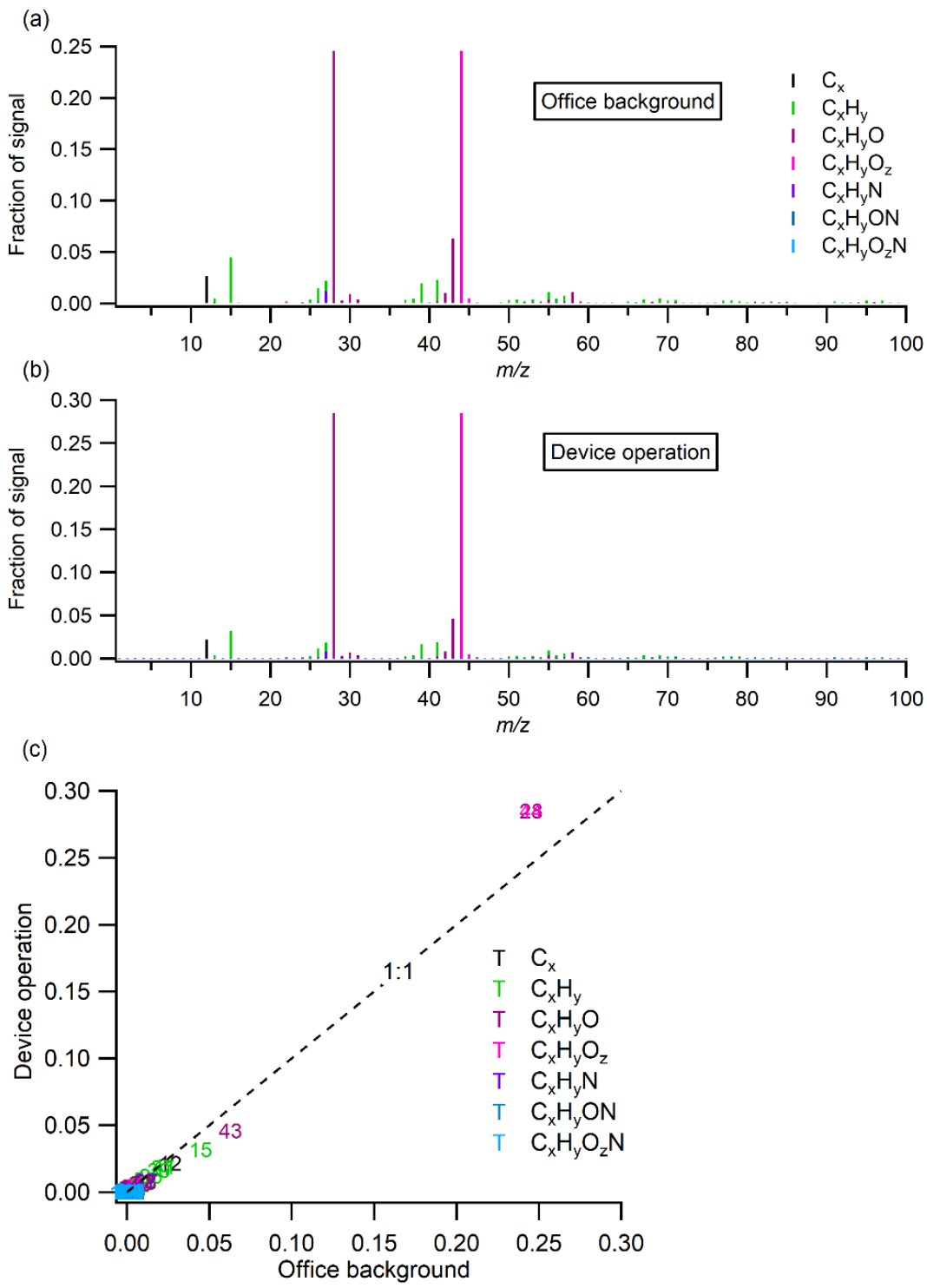

35 Figure S5. Organic families mass spectra of (a) office background and (b) during device operation and (c) the comparison of the organic families mass spectra between (a) and (b). 
(a)

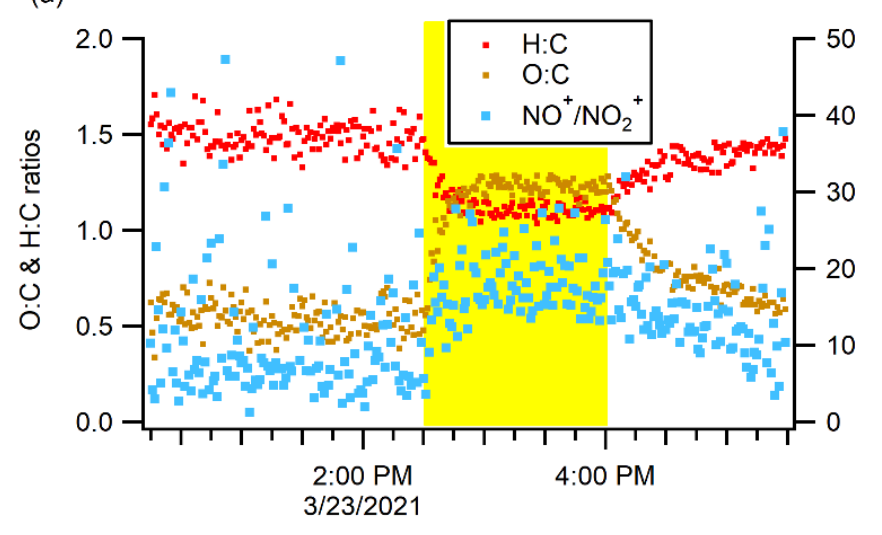

(b)

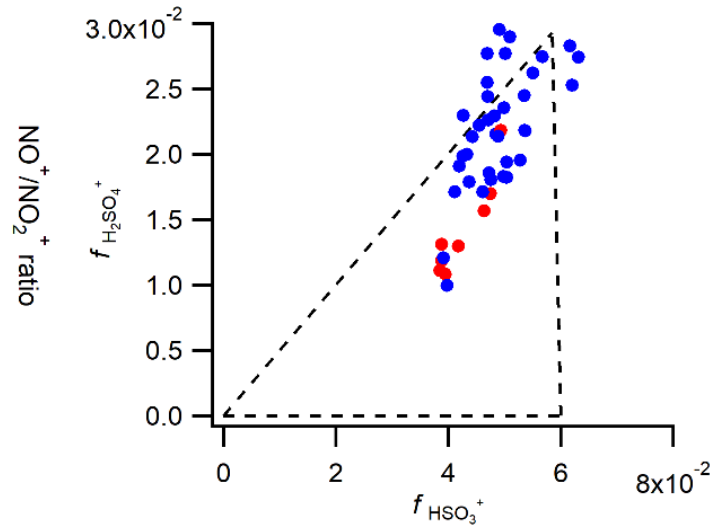

Figure S6. (a) Time series of $\mathrm{H}: \mathrm{C}, \mathrm{O}: \mathrm{C}$, and $\mathrm{NO}^{+} / \mathrm{NO}_{2}{ }^{+}$ratio from the office measurements, with the device operation period highlighted in yellow. (b) $f_{\mathrm{H} 2 \mathrm{SO} 4+}$ vs. $f_{\mathrm{HSO} 3+}$ during the experiment. $f_{\mathrm{H} 2 \mathrm{SO} 4+}$ and $f_{\mathrm{HSO} 3+}$ are the fractions of $\mathrm{H}_{2} \mathrm{SO}_{4}{ }^{+}$and $\mathrm{HSO}_{3}{ }^{+}$in $\mathrm{H}_{\mathrm{x}} \mathrm{SO}_{\mathrm{y}}{ }^{+}$fragments $\left(\mathrm{SO}^{+}, \mathrm{SO}_{2}{ }^{+}, \mathrm{SO}_{3}{ }^{+}, \mathrm{HSO}_{3}{ }^{+}\right.$, and $\mathrm{H}_{2} \mathrm{SO}_{4}{ }^{+}$), respectively. Both fractions approach zero when organic sulfate contribution to total sulfate increases. ${ }^{3}$ Data are 10-min averaged data. The blue data points correspond to office background and the red data points correspond to device operation. The two blue data points at around [0.04, 0.01] are the data points immediately after the device was turned off.

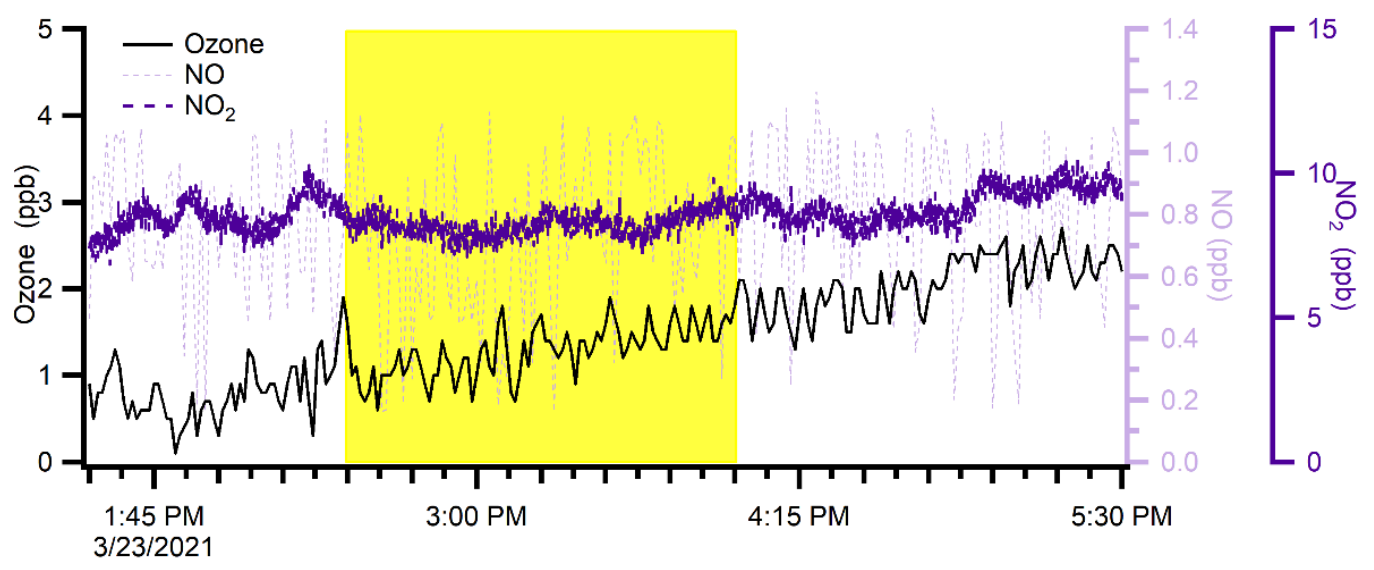

Figure S7. Time series of ozone, $\mathrm{NO}$, and $\mathrm{NO}_{2}$ from the office measurements. The device was in operation from 2:30 pm to 4:00 pm (highlighted in yellow). 


\section{References}

1. Kuwata, M.; Zorn, S. R.; Martin, S. T., Using Elemental Ratios to Predict the Density of Organic Material Composed of Carbon, Hydrogen, and Oxygen. Environmental Science \& Technology 2012, 46 (2), 787-794.

2. Engelhart, G. J.; Hildebrandt, L.; Kostenidou, E.; Mihalopoulos, N.; Donahue, N. M.; Pandis, 60 S. N., Water content of aged aerosol. Atmos. Chem. Phys. 2011, 11 (3), 911-920.

3. Chen, Y.; Xu, L.; Humphry, T.; Hettiyadura, A. P. S.; Ovadnevaite, J.; Huang, S.; Poulain, L.; Schroder, J. C.; Campuzano-Jost, P.; Jimenez, J. L., et al., Response of the Aerodyne Aerosol Mass Spectrometer to Inorganic Sulfates and Organosulfur Compounds: Applications in Field and Laboratory Measurements. Environmental Science \& Technology 2019, 53 (9), 5176-5186. 